\title{
Improvement in health-related quality of life after lung transplantation
}

\author{
Maria-Jose Santana $\mathrm{PhD}^{1}$, David Feeny $\mathrm{PhD}^{2}$, Katherine Jackson $\mathrm{RN}^{3}$, Justin Weinkauf $\mathrm{MD}^{1}$, Dale Lien $\mathrm{MD}^{1}$
}

M-J Santana, D Feeny, K Jackson, J Weinkauf, D Lien. Improvement in health-related quality of life after lung transplantation. Can Respir J 2009;16(5):153-158.

BACKGROUND/OBJECTIVE: Traditional survival outcomes do not reflect the effects on the health-related quality of life (HRQL) of patients. HRQL following lung transplantation has not been studied systematically. The Health Utilities Index (HUI) is a family (HUI2 and HUI3) of measures of HRQL that has not been previously used to assess HRQL in lung transplantation. The objective of the present study was to assess the impact of lung transplantation on patient's HRQL using the HUI.

METHODS: A total of 43 patients completed a battery of questionnaires before lung transplantation, and at three months and six months after lung transplantation. The 15 -item questionnaire (HUI2 and HUI3) was used. Overall scores were based on a conventional scale $(0.00=$ dead, $1.00=$ perfect health). Mental health was assessed by the Hospital Anxiety and Depression Scale. Adherence to medication and exercise were assessed by Morisky's and Godin's questionnaires, respectively.

RESULTS: Sixty-five per cent of the patients were men, with a mean age of 53 years (range 18 to 67 years). The mean overall HUI3 score for the lung transplant candidates $(0.57)$ was much lower than for the lung transplant recipients $(0.82)$ at six months post-transplantation. This difference was clinically important and statistically significant $(\mathrm{P}<0.05$ [paired $t$ test, degrees of freedom $(\mathrm{df})=35]$ ). Differences in mean Hospital Anxiety and Depression Scale scores after transplantation were statistically significant $(\mathrm{P}<0.05$ [paired $t$ test, $\mathrm{df}=35])$. After six months, transplant recipients were more adherent to medication $\left(\mathrm{P}<0.05\left[\chi^{2}\right.\right.$ test, $\left.\left.\mathrm{df}=1\right]\right)$. Recipients were able to increase the duration of exercise at all levels of intensity.

CONCLUSION: Lung transplantation improved the patients' HRQL and adherence to medication. Anxiety levels persisted six months after transplantation but depression levels had decreased significantly.

Key Words: Adherence; Health-related quality of life; Health utility index; Lung transplantation; Mental health

Tn 2007, a total of 2169 lung transplantations were performed worldwide (1). The one-year survival rate is reported to be $82 \%$ and slightly more than $48 \%$ after five years (2).

Traditionally, survival has been used as the main outcome measure after lung transplantation. However, lung transplantation may also have substantial effects on the health-related quality of life (HRQL) of patients. HRQL is a patient-reported outcome that assesses the patient's perceptions of the impact of disease and its treatment. To date, HRQL following lung transplantation has not been studied systematically, particularly in the early stages after transplantation, in which the effects on HRQL may be very dramatic.

Our study is one of the few that describes patients' HRQL during the first six months post-transplantation. Most of the lung transplant literature has focused on long-term HRQL outcomes. It is crucial to explore recipients' HRQL during the first six months post-transplantation because it is an important period of patient adaptation that it is often neglected.

\section{L'amélioration de la qualité de vie liée à la santé après une greffe de poumon}

HISTORIQUE ET OBJECTIF : Les issues de survie classiques ne
tiennent pas compte des effets sur la qualité de vie liée à la santé (QVLS)
des patients. La QVLS après une greffe de poumon n'a fait l'objet d'aucune
étude systématique. Le Health Utility Index (HUI) est une famille (HUI2 et
HUI3) de mesures de la QVLS qui n'a jamais été utilisé auparavant pour
évaluer la QVLS chez les greffés du poumon. La présente étude visait à
évaluer les répercussions de la greffe de poumon sur la QVLS des patients
au moyen de l'HUI. MÉTHODOLOGIE : Au total, 43 patients ont rempli une série de questionnaires avant leur greffe du poumon, puis trois mois et six mois après la greffe. On a utilisé le questionnaire à 15 questions (HUI2 et HUI3). Les résultats globaux se fondaient sur une échelle classique $(0=$ mort, $1=$ parfaite santé). L'échelle d'anxiété et de dépression en milieu hospitalier a permis d'évaluer la santé mentale. Enfin, les questionnaires de Monsky et de Godin, respectivement, ont servi à évaluer le respect de la médication et du plan d'exercice.

RÉSULTATS : Soixante-cinq pour cent des patients étaient des hommes, d'un âge moyen de 53 ans (plage de 18 à 67 ans). L'indice moyen global de l'HUI chez les candidats à la greffe de poumon $(0,57)$ était beaucoup plus bas que chez les greffés du poumon $(0,82)$ six mois après la greffe. Cette différence était importante d'un point de vue clinique et statistiquement significative $(\mathrm{P}<0,05$ [test $t$ pour échantillons appariés, degrés de liberté $(\mathrm{dl})=35])$. Les différences dans les indices moyens de l'échelle d'anxiété et de dépression en milieu hospitalier étaient statistiquement significatives $\left(\mathrm{P}<0,05\right.$ [test $\left.\left.\chi^{2}, \mathrm{dl}=1\right]\right)$. Les greffés étaient en mesure d'accroitre leur durée d'exercice à tous les degrés d'intensité.

CONCLUSION : La greffe du poumon améliorait la QVLS des patients et le respect de la médication. Les taux d'anxiété persistaient six mois après la greffe, mais les taux de dépression avaient diminué de manière significative.

The primary objective of the present study was to assess the impact of lung transplantation on a patient's HRQL. Secondary objectives included assessments of adherence to medication, exercise and mental health. To assist in interpreting scores, we also compared HRQL scores for the pretransplant and six-month post-transplant patients with Canadian norms.

\section{Patients and procedures}

\section{METHODS}

The study was conducted at the lung transplant outpatient clinic at the University of Alberta Hospital, Edmonton, Alberta. Patients were excluded if they were younger than 18 years of age, diagnosed as being cognitively impaired or unable to complete questionnaires in English. Written information about the study was provided to patients before obtaining informed consent. Ethics approval was obtained from the University of Alberta Health Research Ethics Board, Panel B.

\footnotetext{
${ }^{1}$ Division of Pulmonary Medicine, University of Alberta Hospital, Edmonton, Alberta; ${ }^{2}$ Center for Health Research Northwest, Kaiser Permanente Northwest, Portland, USA; ${ }^{3}$ Lung Transplant Program, University of Alberta Hospital, Edmonton, Alberta

Correspondence: Dr Dale Lien, Division of Pulmonary Medicine, University of Alberta Hospital, 8440112 Street Northwest,

2E4.33 Walter C Mackenzie Centre, Edmonton, Alberta T6G 2B7. Telephone 780-407-1632, fax 780-407-6384, e-mail dale.lien@ualberta.ca
} 


\section{Measures}

After enlisting (baseline), patients completed a battery of questionnaires described below. The time period before lung transplantation varied between one and 26 weeks.

\section{Health Utilities Index}

The Health Utilities Index Mark 3 (HUI3) is a generic, multiattribute, preference-based measure of HRQL. Generic HRQL measures are intended to provide information on general function and well-being. HUI3, however, assesses the full range of health among diverse groups of patients and reflects the impact of comorbidities. HUI3 has been widely used and included in every major population health survey performed in Canada since 1990 (3).

HUI3 includes eight attributes (vision, hearing, speech, ambulation, dexterity, cognition, emotion and pain), with five or six levels for each attribute $(3,4)$. HUI3 describes a total of 972,000 unique health states and provides overall scores on a conventional scale $(0.00=$ dead to $1.00=$ perfect health $)$ so that morbidity and mortality can be integrated and quality-adjusted survival can be estimated. HUI3 single-attribute utility scores are based on a scale in which the score for the most highly impaired level is 0.00 and the score for normal is 1.00 .

Differences of 0.03 or more in overall HUI3 scores are clearly clinically important, and differences as small as 0.01 may be meaningful and important in some contexts $(3,5,6)$. Differences of 0.05 or more in the single-attribute utility scores are clearly clinically important (3).

To assist in the interpretation of overall HUI3 utility scores, ranges of overall scores are classified in the following disability categories: no disability, mild disability, moderate disability and severe disability (7). Similarly, each level in each attribute of the HUI3 corresponds to one of the categories: no disability, mild disability, moderate disability or severe disability.

Given the burden associated with lung disease, specifically diseases severe enough to warrant consideration for transplantation, particular attributes in the HUI3 are likely to be especially relevant and include HUI3 ambulation, which assesses physical functioning, HUI3 pain and discomfort, and HUI3 emotion. HUI3 was assessed at baseline, at the first clinic visit after transplantation, and at three and six months posttransplantation.

\section{Canadian National Population Health Survey}

Data from the Canadian National Population Health Survey 1996/1997 (cycle 2) conducted by Statistics Canada (data specifically from the survey of community-dwelling residents) was used to establish normative comparisons for pretransplant and six-month post-transplant HRQL scores (8).

\section{The Hospital Anxiety and Depression Scale}

Mental health issues may be important as patients wait for a suitable organ donor, undergo transplantation and adjust to immunosuppressive medications. Both anxiety and depression are potentially relevant. The Hospital Anxiety and Depression Scale (HADS [9]) is a self-completed mental health measure that takes $2 \mathrm{~min}$ to $5 \mathrm{~min}$ to complete and has been shown to be a valid and reliable measure. The HADS uses a one-week recall period. The scale consists of 14 items: seven that assess anxiety and seven that assess depression. Each item is based on a 4-point scale in which scores are added to give a total ranging from 0 to 21 for anxiety and 0 to 21 for depression. Higher scores indicate higher severity of anxiety or depression. Scores of between 8 and 10 identify mild cases, 11 to 15 identify moderate cases, and scores of 16 or higher represent a severe case (10). A difference of two units between current and previous assessments is clinically important. The patients completed the HADS at baseline and at six months post-transplantation.

\section{Measures of adherence}

Adherence to medication and exercise is an importasnt contributor to the success of transplantation. Two measures of adherence were included in the present study:

1. Godin and Shephard's (11) survey measures daily physical activities and exercise. This measure is valid, reliable and easy to complete.

2. The Morisky et al (12) measure of medication adherence is widely used. It contains four questions regarding medication use patterns. It is valid, reliable and easy to complete.

The adherence measures were obtained at baseline and at six months post-transplantation.

\section{Statistical analysis}

Descriptive statistics are provided for single-attribute scores and overall HUI utility scores at pre- and postlung transplant assessments for the cohort of patients who underwent lung transplantation. Mean single-attribute scores and overall utility scores at six months and at baseline were compared using the paired $t$ test. Imputation of the last value carried forward was the method used to account for missing data.

Mean overall HUI utility scores for pretransplant and six months post-transplant were compared with Canadian normative data. The population norm for Canada with which to compare the lung transplant cohort was calculated by imposing the age-sex distribution of the patients onto the normal population data.

Mean HADS anxiety and depression scores were compared before and after transplantation using the paired $t$ test. For categorical variables, the $\chi^{2}$ test was used to compare the Morisky et al (12) (adherence to medication) scores at baseline and six months after transplantation. Adherence to exercise between baseline and six-month post-transplant measures was analyzed using the paired $t$ test.

All tests of significance were two-sided and results were considered to be statistically significant at $\mathrm{P}<0.05$. Analyses were performed using SPSS 15.0 software, version 13 (SPSS Inc, USA).

\section{RESULTS}

Longitudinal data covering both pre- and post-transplant experience were available for 43 patients. Consecutive patients were recruited and measured at baseline (pretransplant), at the first post-transplant visit to the outpatient clinic, and at three and six months after lung transplantation. Seven male (no female) patients died before completing follow-up. Two patients withdrew from the study after the three-month visit (one man and one woman, who gave no specific reason for withdrawl).

\section{Patient characteristics}

The demographic and clinical characteristics of the 43 patients are summarized in Table 1 . Thirty-six patients had a double 
lung transplant, three patients a left lung transplant, two patients underwent a heart and double lung transplant, one had a right lung and one had a living-related lobar lung transplant. Of the seven male patients who died, six had been diagnosed with idiopathic pulmonary fibrosis and one with chronic obstructive pulmonary disease.

Significant differences in the 6 min walk test $(\mathrm{P}=0.02)$ were detected between pretransplant $(353 \mathrm{~m})$ and post-transplant $(428 \mathrm{~m})$ subjects. Similarly, the difference between the forced expiratory volume in $1 \mathrm{~s}\left(\mathrm{FEV}_{1}\right)$ per cent predicted at pretransplant (33\% predicted) and post-transplantation (64\% predicted) was statistically significant $(\mathrm{P}=0.001)$.

\section{Descriptive statistics}

Outcomes for all survivors are presented in Table 2. Results from Table 2 reveal clinically important and statistically significant gains in HRQL. The baseline mean overall HUI3 scores before transplantation (0.57) indicate severe disability. The baseline HUI3 ambulation and pain scores indicate moderate disability, while the baseline HUI3 emotion score indicates mild disability.

The mean overall HUI3 score was 0.82 at the six-month assessment, a very substantial improvement of 0.25 in the overall HUI3 score relative to pretransplantation (Table 2). At the six-month assessment, little disability was evident in the mean HUI3 ambulation and emotion scores, with the mean HUI3 pain score indicating mild disability. The overall score indicated moderate disability.

Clinically important (and statistically significant) improvements were observed in single-attribute utility scores for ambulation, emotion, pain and in the overall HUI3 score at six months post-transplant.

Examining HUI3 results, lung transplantation was associated with very substantial reductions in ambulation disability and pain, and modest improvements in mental health. Lung transplantation is also associated with a very substantial increase in overall HRQL.

Comparing overall HUI3 scores with Canadian norms with respect to age and sex

Table 3 displays overall pretransplant and post-transplant HUI3 scores for men and women, and Canadian norms. The population norm for Canada with which to compare the lung transplant cohort was calculated by imposing the age-sex distribution of the cohort onto the population norm data. Men in
TABLE 1

Demographic and clinical characteristics $(n=43)$

\begin{tabular}{|c|c|}
\hline Age, years (mean [range]) & $53(18$ to 67$)$ \\
\hline Male sex & 65 \\
\hline \multicolumn{2}{|l|}{ Respiratory diagnosis } \\
\hline Chronic obstructive pulmonary disease & 44.2 \\
\hline Idiopathic pulmonary fibrosis & 30.2 \\
\hline Primary pulmonary hypertension & 7.0 \\
\hline Cystic fibrosis & 16.3 \\
\hline Other & 2.3 \\
\hline \multicolumn{2}{|l|}{ Marital status } \\
\hline Married & 72 \\
\hline Single & 14 \\
\hline Divorced & 7 \\
\hline Common law & 7 \\
\hline \multicolumn{2}{|l|}{ Education level } \\
\hline No schooling & 2 \\
\hline Elementary & 7 \\
\hline Junior high school & 14 \\
\hline High school & 40 \\
\hline College certificate & 21 \\
\hline \multicolumn{2}{|l|}{ University degree } \\
\hline Undergraduate & 12 \\
\hline Graduate & 4 \\
\hline \multicolumn{2}{|l|}{ Employment status } \\
\hline Disabled & 42 \\
\hline Retired & 23 \\
\hline Unemployed & 12 \\
\hline Part-time & 16 \\
\hline Full-time & 7 \\
\hline
\end{tabular}

Data presented as \%, unless otherwise indicated

the cohort were, on average, nearly 10 years older than women. The Canadian HUI3 norm for men is 0.89 and 0.90 for women, both basically indicative of mild disability. At pretransplant, the gap between patients and the population norm was very substantial. At six months post-transplant, the gap was much smaller.

\section{Mental health}

Following transplantation, the mean HADS scores for anxiety and depression were lower (Table 4). After transplantation,

TABLE 2

Survivor single-attribute utility scores and overall utility scores for the Health Utilities Index Mark 3 (HUI3) ( $n=36$ )

\begin{tabular}{|c|c|c|c|c|c|}
\hline \multirow[b]{3}{*}{ Attribute } & \multirow{3}{*}{$\begin{array}{l}\text { Pretransplant } \\
\text { Mean } \pm \text { SD }\end{array}$} & \multicolumn{3}{|c|}{ Post-transplant score } & \multirow{2}{*}{$\begin{array}{l}\text { Six-month post-transplant score } \\
\text { minus pretransplant score }\end{array}$} \\
\hline & & First visit & Three months & Six months & \\
\hline & & Mean \pm SD & Mean \pm SD & Mean \pm SD & Change \\
\hline HUI3 vision & $0.93 \pm 0.16$ & $0.94 \pm 0.08$ & $0.96 \pm 0.05$ & $0.95 \pm 0.08$ & 0.02 \\
\hline HUI3 hearing & $0.94 \pm 0.19$ & $0.96 \pm 0.11$ & $0.98 \pm 0.08$ & $0.97 \pm 0.09$ & 0.03 \\
\hline HUI3 speech & $0.99 \pm 0.04$ & $0.98 \pm 0.06$ & $0.98 \pm 0.07$ & $0.99 \pm 0.02$ & 0.00 \\
\hline HUI3 ambulation & $0.66 \pm 0.26$ & $0.75 \pm 0.22$ & $0.90 \pm 0.15$ & $0.95 \pm 0.10$ & $0.29 * \dagger$ \\
\hline HUI3 dexterity & $1.00 \pm 0.00$ & $0.96 \pm 0.13$ & $0.98 \pm 0.09$ & $0.97 \pm 0.10$ & -0.03 \\
\hline HUI3 emotion & $0.93 \pm 0.08$ & $0.98 \pm 0.04$ & $0.96 \pm 0.08$ & $0.98 \pm 0.04$ & $0.05^{\star \dagger}$ \\
\hline HUI3 cognition & $0.94 \pm 0.11$ & $0.97 \pm 0.07$ & $0.96 \pm 0.09$ & $0.95 \pm 0.10$ & 0.01 \\
\hline HUI3 pain & $0.75 \pm 0.31$ & $0.79 \pm 0.16$ & $0.86 \pm 0.16$ & $0.90 \pm 0.12$ & $0.15^{\star \dagger}$ \\
\hline Overall HUI3 & $0.57 \pm 0.27$ & $0.65 \pm 0.21$ & $0.77 \pm 0.20$ & $0.82 \pm 0.17$ & $0.25^{\star} \dagger$ \\
\hline
\end{tabular}

*Statistically significant $(P<0.05)$. ${ }^{\dagger}$ Clinically important difference 
TABLE 3

Comparison of pre- and post-lung transplant overall Health Utilities Index Mark 3 (HUI3) scores with Canadian norms

\begin{tabular}{lccc}
\hline & \multicolumn{3}{c}{ Overall HUl3 scores } \\
\cline { 2 - 4 } Sex & Pretransplant & Post-transplant & Canadian norm \\
\hline Male & $0.57 \pm 0.27$ & $0.82 \pm 0.16$ & 0.89 \\
Female & $0.53 \pm 0.27$ & $0.84 \pm 0.17$ & 0.90 \\
\hline
\end{tabular}

Data presented as mean $\pm S D$

TABLE 4

Comparison of pre- and post-lung transplant mental health Hospital Anxiety and Depression Scale scores

\begin{tabular}{|c|c|c|c|}
\hline & Pretransplant & $\begin{array}{c}\text { Six months } \\
\text { post-transplant } \\
\end{array}$ & $\begin{array}{c}\text { Six months } \\
\text { post-transplant minus } \\
\text { pretransplant score }\end{array}$ \\
\hline & Mean \pm SD & Mean \pm SD & Change \\
\hline Anxiety & $6.65 \pm 3.49$ & $5.81 \pm 3.67$ & 0.84 \\
\hline Depression & $5.72 \pm 2.71$ & $3.58 \pm 3.03$ & $2.14^{* \dagger}$ \\
\hline
\end{tabular}

${ }^{*}$ Statistically significant $(P<0.05) .{ }^{+}$Clinically important difference

$29.4 \%$ of patients had borderline or clinical anxiety, and only $9 \%$ of the patients had signs of depression. There was a statistically significant and clinically important difference in mean HADS depression scores before and after transplantation $(\mathrm{P}<0.05$ [paired $t$ test]). The difference in mean HADS anxiety scores was neither statistically significant nor clinically important.

\section{Adherence}

At six months, transplant recipients were able to increase the duration (min) of exercise in all three levels of intensity (mild, moderate and strenuous) (Table 5). The most substantial increase was at the moderate level. However, the statistical test showed no statistically significant differences between baseline and the six-month post-transplant scores.

Following lung transplantation, patients were more adherent to medication (Table 6). There was a statistically significant difference after transplantation $\left(\mathrm{P}<0.05\left[\chi^{2}\right.\right.$ test, $\mathrm{df}=1$, $\alpha=0.025]$ ).

\section{DISCUSSION}

The present study provided comprehensive evidence that lung transplantation improved patients' HRQL during the first six months post-transplantation. The pretransplant HUI3 scores confirmed the considerable impairment experienced by the patients. Substantial improvements at six months post-transplantation are evident in emotion, ambulation, pain and overall HRQL.

The overall gain in HRQL observed among survivors (0.25) compares favourably with the 0.23 gain observed in a cohort of patients undergoing elective total hip arthroplasty (13). These findings are consistent with previous studies. Several studies (14-17) have reported improvements in the HRQL of post-transplant patients within four months and that this improvement was maintained in the long term. The studies cited used different HRQL measures. Three studies (14-16) used health profile measures, The Nottingham Health Profile, RAND-36 item health survey and the Sickness Impact Profile, respectively. One study (17) used a preference-based measure, the EuroQol-5D. The present study used a preference-based measure - the HUI. It is the first time that the HUI has been used in lung transplantation. One of the advantages of using the HUI is the ability to compare data with Canadian population norms. Before transplantation, the cohort of patients was well below Canadian population HUI norms. At six months after transplantation, patient scores remained below population norms but the gap was much smaller. HRQL scores for patients post-transplant indicate a moderate burden of illness, whereas at pretransplant the burden was severe.

Psychological problems are related to poor post-transplant outcomes, such as nonadherence, increased risk of acute rejection and increased duration of hospitalization (18). Previous studies (19) confirm that the prevalence of anxiety is high in patients with lung disease.

Our results indicate reductions in depression while anxiety persisted (perhaps recipients worry about the possible consequences of transplantation). Similarly, two studies $(14,20)$ found no significant differences in anxiety levels between preand post-transplant patients. Limbos et al (15) and Rodrigue et al (21) also found no significant improvements in psychological function scores over time.

Exercise improved after transplantation, although the difference was not statistically significant. Improvements in ambulation and pain were noted, and the 6 min walk test showed a clinically important and statistically significant improvement at six months post-transplant.

Adherence to medication is not easy to assess and has not been routinely studied in lung transplantation. Desmyttere et al (22) estimated that $20 \%$ to $25 \%$ of adult heart, liver and renal transplant patients were nonadherent to their immunosuppressive therapy. Nonadherent patients have a greater risk of acute rejections and lower HRQL (23).

In the present study, the Morisky et al (12) scale was used to assess adherence to medication. It has been widely used and shown to be responsive and reliable. Following lung transplantation, patients were more adherent to medication. There was a statistically significant difference in the proportion of patients who never forgot to take their medications after transplantation $\left(\mathrm{P}<0.05\left[\chi^{2}\right.\right.$ test, $\left.\left.\mathrm{df}=1, \alpha=0.025\right]\right)$. This increase in adherence could be the result of the intense, continuous education and

\section{TABLE 5}

Exercise frequency per week (T) and duration (D) for three different levels of exercise intensity at baseline (pretransplant) and at six months post-transplant

\begin{tabular}{|c|c|c|c|c|c|c|c|c|c|c|c|c|}
\hline & \multicolumn{6}{|c|}{ Pretransplant exercise intensity } & \multicolumn{6}{|c|}{ Six-month post-transplant exercise intensity } \\
\hline & \multicolumn{2}{|c|}{ Mild } & \multicolumn{2}{|c|}{ Moderate } & \multicolumn{2}{|c|}{ Strenuous } & \multicolumn{2}{|c|}{ Mild } & \multicolumn{2}{|c|}{ Moderate } & \multicolumn{2}{|c|}{ Strenuous } \\
\hline & $T$ & D & $T$ & D & $\mathbf{T}$ & D & $T$ & D & $\mathbf{T}$ & D & $T$ & D \\
\hline Mean & 1.89 & 17.25 & 2.69 & 24.44 & 2.22 & 10.04 & 2.06 & 25.83 & 3.25 & 33.75 & 1.22 & 15 \\
\hline
\end{tabular}

There was no statistically significant difference between pretransplant and six-month post-transplant measures. Exercise duration presented in minutes. Data adapted from reference 11 
training provided to patients by the transplant coordinators and transplant respirologists during the transplant process.

There are several potential limitations in the present study. The sample size of 36 patients for whom longitudinal data were available is moderate and limits the statistical power of the analyses. However, due to death and loss to follow-up, it is difficult to conduct longitudinal studies in lung transplantation. Some of the longitudinal studies (21) excluded the first six-month period. Furthermore, most of the studies are crosssectional, comparing different patients at different stages of transplantation. We believe that the first six-month period post-transplantation may have an important impact on a patient's HRQL and it is important to document the experience in this interval.

Follow-up was conducted to six months post-transplant and may not reflect the subsequent onset of additional complications, declines in adherence or the cumulative effects of immunosuppressants. The improvement detected in patients' HRQL six months post-transplantation in our study is consistent with results reported by Littlefield et al (24). They reported that any improvements post-transplantation were evident within the first six months. Furthermore, Stavern et al (25) confirmed that there were no differences between groups of recipients assessed later than six months, indicating that the HRQL does not deteriorate much over time. It seems that the major improvement in HRQL occurs within six to 12 months after transplantation; HRQL then reaches a plateau. The most common cause of decrease in HRQL is due to broncholitis obliterans syndrome, which commonly develops two years after transplantation $(21,26)$.

Results of the present study were obtained from patients seen at a highly specialized, multiprovince, tertiary care clinic and may not be generalizable to other clinical settings. Furthermore, the study was an observational one. We have documented the gains in HRQL associated with lung transplantation using a before-after design. Although there was no control group, patients were followed throughout transplantation; consequently, each patient acted as their own control. Patients were not randomly assigned to receive or not receive lung transplantation. However, within the cohort of patients deemed eligible for lung transplantation, those who received a lung were individuals for whom a suitable size and blood group match was available - this availability may be regarded as a quasirandom process.

\section{CONCLUSION}

The first six months post-transplantation is associated with significant improvements in HRQL. We were able to document very substantial gains in physical health (ambulation), reductions in pain and discomfort, reductions in depression and significant improvements in the overall HRQL of surviving patients. We were also able to observe improvements in adherence to both exercise and medication. Although at six months post-transplant, patients' HRQL did not reach the levels seen in the general Canadian population, the improvement from pretransplant to post-transplant is substantial. The present study was the first to use the HUI3 in lung transplantation and to establish comparisons with Canadian population norms. Results indicate that the HUI3 was able to capture both the burden of lung disease before transplantation and meaningful improvements after transplantation.
TABLE 6

Results for the Morisky measure of adherence to medication

\begin{tabular}{|c|c|c|c|c|}
\hline \multirow[b]{2}{*}{ Question } & \multicolumn{2}{|c|}{$\begin{array}{l}\text { Pre- } \\
\text { transplant }\end{array}$} & \multicolumn{2}{|c|}{$\begin{array}{l}\text { Six months } \\
\text { post- } \\
\text { transplant }\end{array}$} \\
\hline & Yes & No & Yes & No \\
\hline $\begin{array}{l}\text { Q1. Do you ever forget to take your } \\
\text { medication? }\end{array}$ & 29 & 71 & $9^{*}$ & $91^{*}$ \\
\hline $\begin{array}{l}\text { Q2. Are you careless about taking your } \\
\text { medications? }\end{array}$ & 3 & 97 & 0 & 100 \\
\hline $\begin{array}{l}\text { Q3. When you feel better, do you sometimes } \\
\text { stop taking your medications? }\end{array}$ & 6 & 94 & 0 & 100 \\
\hline $\begin{array}{l}\text { Q4. Sometimes if you feel worse when you } \\
\text { take your medication, do you stop taking } \\
\text { them? }\end{array}$ & 11 & 89 & 3 & 97 \\
\hline
\end{tabular}

ACKNOWLEDGEMENTS: The authors thank Dr Neil Skout, Marianne Schafenacker and Andrea Taskin for their help in the study. Financial support was provided by Roche Pharmaceuticals.

CONFLICTS OF INTEREST: Maria-Jose Santana has no conflicts of interest to disclose. Dr David Feeny has a proprietary interest in Health Utilities Incorporated, Dundas, Ontario. HUInc distributes copyrighted Health Utilities Index (HUI) materials and provides methodological advice on the use of HUI. Katherine Jackson has no conflicts of interest to disclose. Dr Justin Weinkauf has no conflicts of interest to disclose. Dr Dale Lien has no conflicts of interest to disclose.

\section{REFERENCES}

1. <www.ishlt.com>. J Heart Lung Transplant 2007;26:782-95.

2. Lung transplant: A treatment for life-threatening lung disease. <www.mayoclinic.com> (Version current at May 19, 2009).

3. Horsman J, Furlong W, Feeny D, Torrance G. The Health Utilities Index (HUI $囚)$ : Concepts, measurement properties and applications. Health Qual Life Outcomes 2003;1:54.

4. Feeny D, Furlong W, Torrance GW, et al. Multiattribute and singleattribute utility functions for the Health Utilities Index Mark 3 system. Med Care 2002;40:113-28.

5. Grootenstorst P, Feeny D, Furlong W. Health Utility Index Mark 3: Evidence of construct validity for stroke and arthritis in a population health survey. Med Care 2000;38:290-9.

6. Drummond M. Introducing economic and quality of life measurements into clinical studies. Ann Med 2001;33:344-9.

7. Feeny D, Furlong W, Saigal S, Sun J. Comparing directly measured standard gamble scores to HUI2 and HUI3 utility scores: Groupand individual-level comparisons. Soc Sci Med 2004;58:799-809

8. Statistics Canada. National Population Health Survey Cycle 3 Documentation. Catalog \# 82-567.

9. Zigmond AS, Snaith RP. The hospital anxiety and depression scale. Acta Psychiatr Scand 1983;67:361-70.

10. Snaith RP. The hospital anxiety and depression scale. Health Qual Life Outcomes 2003;1:29.

11. Godin G, Shephard RJ. A simple method to assess exercise behavior in the community. Can J Applied Sport Sciences 1985;10:141-6.

12. Morisky DE, Green LW, Levine DM. Concurrent and predictive validity of a self-reported measure of medication adherence. Med Care 1986;24:67-74.

13. Feeny D, Wu L, Eng K. Comparing Short Form 6D, Standard Gamble, and Health Utilities Index Mark 2 and Mark 3 Utility Scores: Results from total hip arthroplasty patients. Qual Life Res 2004;13:1659-70.

14. Ten Vergert E, Essink-Bot ML, Geertsma A, van Enckevort P, de Boer WJ, van der Bij W. The effect of lung transplantation on 


\section{Santana et al}

health-related quality of life: A longitudinal study. Chest 1998;113:358-64.

15. Limbos M, Joyce D, Chan C, Kesten S. Psychological functioning and quality of life in lung transplant candidates and recipients. Chest 2000;118:408-16.

16. Lanuza D, Lefaiver C, Mc Cabe M, Farcas GA, Garrity E Jr. Prospective study of fuctional status and quality of life before and after lung transplantation. Chest 2000;118:115-22.

17. Anyanwu AC, McGuire A, Rogers CA, Murday AJ. Assessment of quality of life in lung transplantation using a simple generic tool. Thorax 2001;56:218-22.

18. Parekh P, Blumenthal J, Babyak MA, et al. Psychiatric disorder and quality of life in patients awaiting lung transplantation. Chest 2003;124:1682-8.

19. Dew MA. Psychiatric disorder in the context of physical illness. In Dohrenwend BP, ed. Adversity, Stress and Psychopathology. Washington, DC: Elsevier Science, 1998.

20. Cohen L, Littlefield C, Kelly P, Maurer J, Abbey S . Predictors of quality of life and adjustment after lung transplantation. Chest 1998;113:633-44.
21. Rodrigue JR, Baz MA, Kanasky WF, MacNaughton KL. Does transplantation improve health-related quality of life? The University of Florida experience. J Heart Lung Transplant 2005;24:755-63.

22. Desmyttere A, Dobbles F, Cleeemput I, De Geest S. Noncompliance with immunosuppressive regimen in organ transplantation: Is it worth worrying about? Act Gastroenterol Belg 2005;68:347-52.

23. Denhaerynck A, Stagier J, Block A, et al. Prevalence and risk factors of nonadherence with immunosuppresive medication in kidney transplant patients. Am J Transplant 2007;7:108-16.

24. Littlefield C, Abbey S, Fiducia D, et al. Quality of life following transplantation of the heart, liver, and lungs. Gen Hosp Psychiatry 1996;18:36S-47S.

25. Stavern K, Bjortuft O, Lund MB, Kongshaung K, Geiran O, Boe J. Health-related quality of life in lung transplant candidates and recipients. Respiration 2000;67:159-65.

26. Gerbase MW, Spiliopoulos A, Rochat T, Archinard M, Nicod LP. Health-related quality of life following single or bilateral lung transplantation: A 7-year comparison to functional outcome. Chest 2005;128:1371-8. 


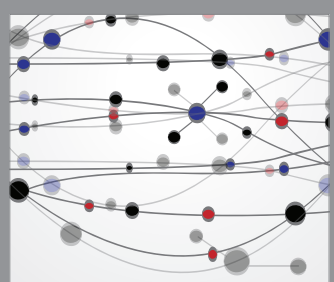

The Scientific World Journal
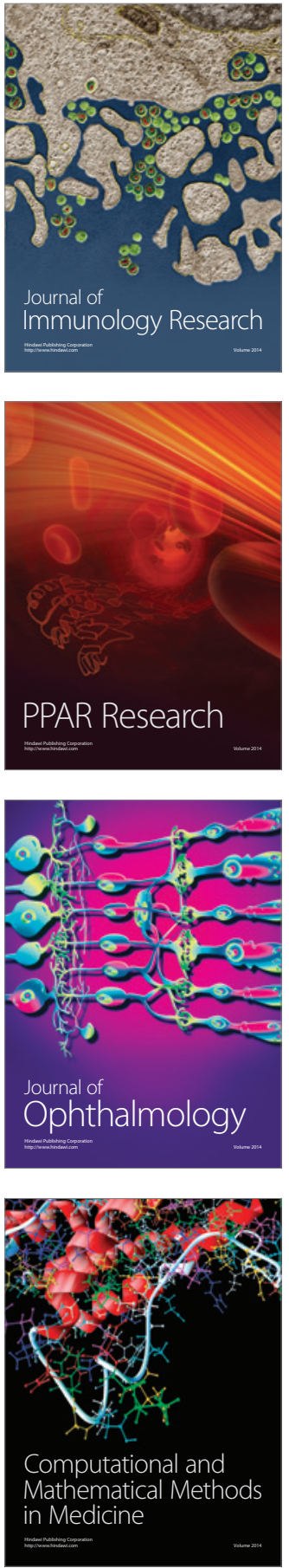

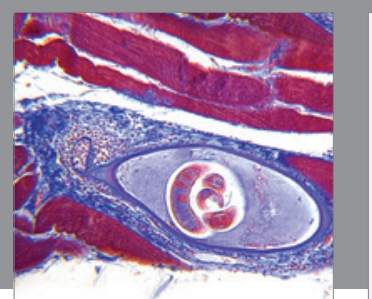

Gastroenterology Research and Practice

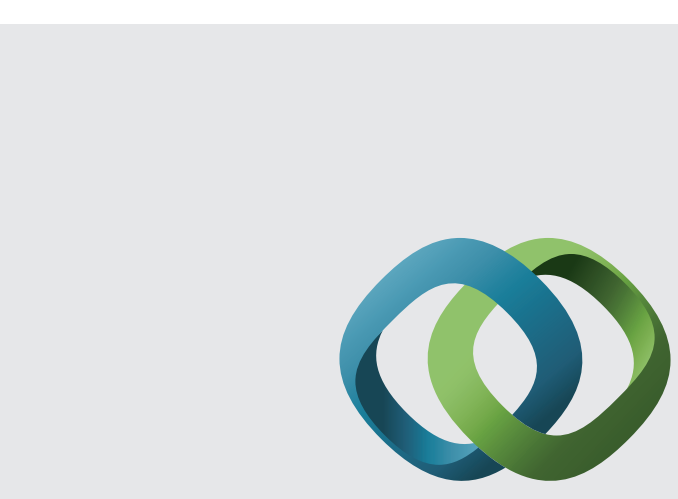

\section{Hindawi}

Submit your manuscripts at

http://www.hindawi.com
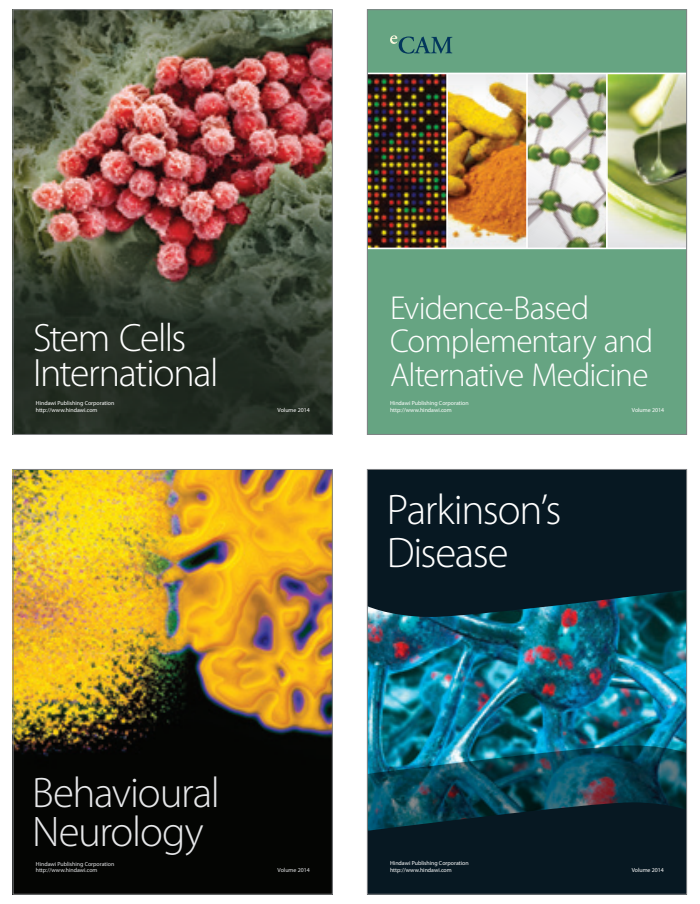
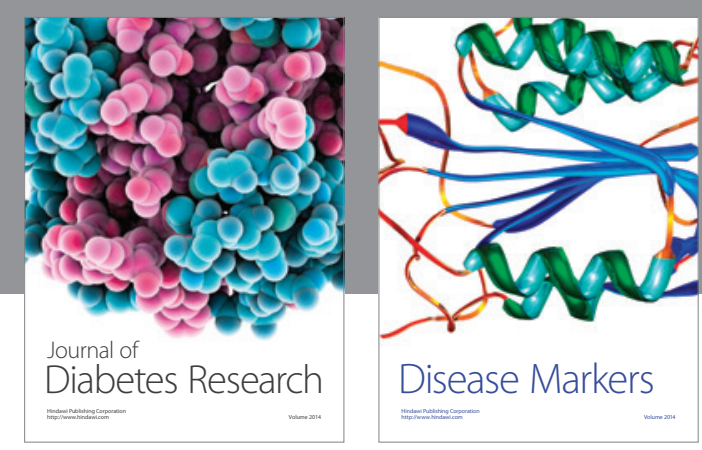

Disease Markers
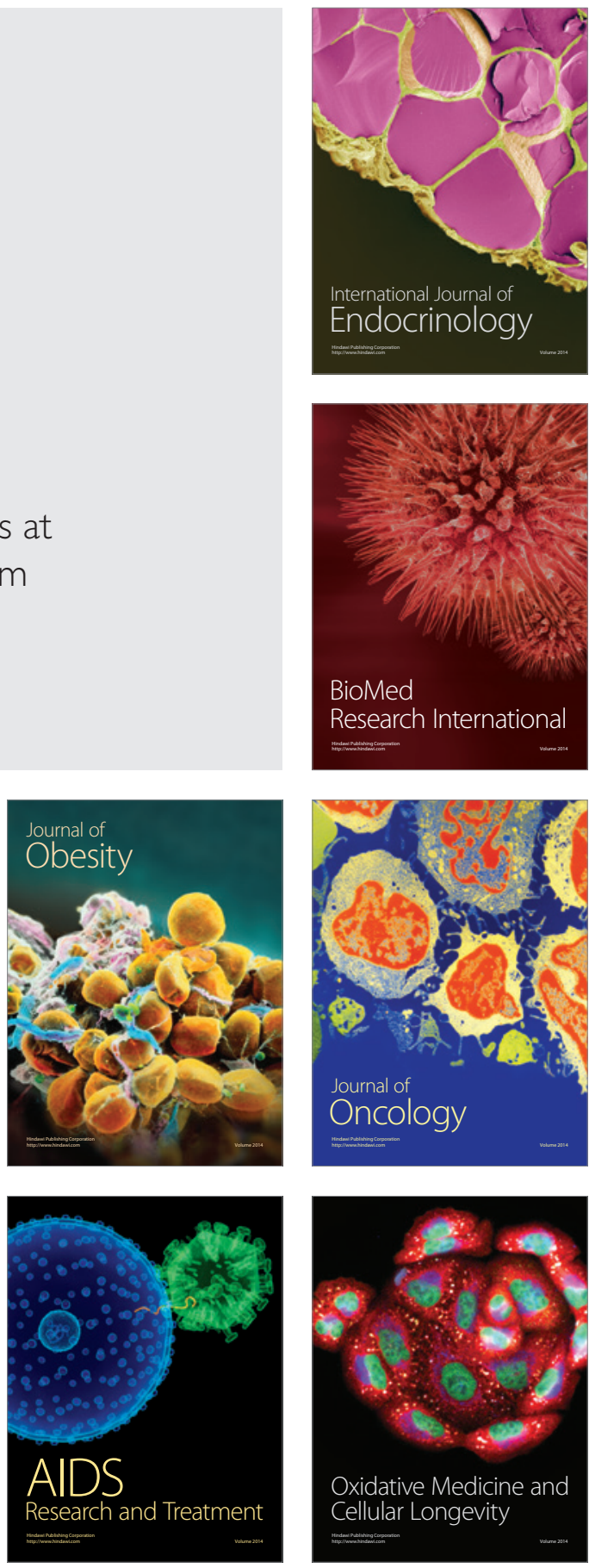